\title{
Collaborative Governance: Analysing Social Audits in MGNREGA in India
}

\author{
Nidhi Vij
}

\begin{abstract}
In the history of social protection programmes in India, the Mahatma Gandhi National Rural Employment Guarantee Act (MGNREGA) is the most expansive and ambitious programme ever. In 2009/10 alone, over 380 billion rupees (US $\$ 8$ billion) were spent to employ over 50 million households under this scheme. To oversee such expansive coverage, an elaborate monitoring and evaluation system has been enshrined in the law. It was also realised that non-state actors need to be included in the monitoring process for collective accountability and ensuring transparency. Social audits are unique collaborative governance mechanisms which are not only participatory programme evaluation exercises but also lead to empowerment of the poor. They are a platform for the vulnerable to raise their 'voice' and assert their 'rights'; to hold the administration accountable and assume collective responsibility, thereby potentially transforming social protection to social justice. This article analyses the social audit framework from a policy design perspective, in light of field reports and recent changes in the rules and aims, to unravel why, despite the merits, it is not yet the 'magic silver bullet' for poverty alleviation.
\end{abstract}

\section{History of wage employment programmes in India}

Since India's independence in 1947, wage employment programmes have been an integral part of social protection policies. Pilot projects until the 1970s gave way to a fully fledged Food for Work Programme (FWP) in 1977 and other employment policies like Jawahar Rozgar Yojana (JRY) (1993-4) and the Employment Assurance Scheme (EAS) (1993). During the late 1990s, with growing emphasis on rural infrastructural development, the programmes were slowly merged into Jawahar Gram Samriddhi Yojana (JGSY), Sampoorna Grameen Rozgar Yojana (SGRY) and finally into the National Food for Work Programme (NFFWP). ${ }^{1}$ However, these programmes were crippled by ineffective design, poor targeting and low awareness about the programme or its provisions, administrative problems, distribution inefficiencies, nontransparent procedures, pilferage and widespread corruption. The results were a mixed bag without any clear indication of what policy design worked best in reducing poverty (Yesudian 2007). Even as the economy grew at an average of 5 per cent per annum, poverty declined at a rate of less than one percentage point per annum, from 46.9 per cent in 1983 to 28.4 per cent in 2005 (Lanjouw and Murgai 2009).

These wage employment programmes aimed at providing economic assistance, without addressing the complexities of the sociopolitical environment that constrain the poor or certain vulnerable people from even accessing these social protection benefits. It must be realised that the economic condition of the poor is inextricably intertwined with social dimensions of wellbeing, equity and social rights (Sabates-Wheeler and Devereux 2007). The Backward Classes and Backward Castes ${ }^{2}$ are often discriminated against and selectively excluded by their communities from participating or benefiting from the programmes. There are certain sections among the poor in rural areas that even today are visibly and passively discriminated against on the basis of gender, class, caste, religion or location by the rest of the community. Social exclusion and structural inequalities are aggravated with the socialpolitical-cultural environment and regional variations across the States. Social protection policies can still play a limited role in addressing these structural inequalities within their design, to effectively target and reach out to the 
vulnerable sections. Social protection policies have to be more than just preventive measures; they should also promote participation of the vulnerable sections in social and political life, contributing to growth and development (Kabeer and Cook 2010). These measures can be transformative if they integrate different sections of the society, while enabling vulnerable groups to claim their rights, reap the benefits of growth and seek social justice by creating a more egalitarian society (Sabates-Wheeler and Devereux 2007).

This article proposes that decentralised collaborative governance models hold the key to more effective implementation and empowerment of the poor. A governing arrangement is collaborative when public agencies directly engage non-state stakeholders in a collective decision-making process that is formal, consensus-oriented and deliberative and that aims to make or implement public policy or manage public programmes or assets (Ansell and Gash 2008). Furthermore, empowerment should be seen as a process through which the poor, excluded and vulnerable sections of society are informed of their rights and entitlements, so they can participate and influence the governance process and eventually integrate with the mainstream discourse. Collaborative governance and empowerment are the missing links that bridge social protection and social justice.

The following sections analyse the Mahatma Gandhi National Rural Employment Guarantee Act (MGNREGA) - a social protection programme in India - and its unique social audit mechanism for monitoring. It reveals how improving the design of social protection policies and building the capacities of the poor to exercise their rights can translate into social justice. The article concludes that social protection programmes must incorporate a rights-based approach within their design and should provide a 'space' within the policy framework for the poor to exercise their rights and hold the implementing agencies accountable.

\section{Mahatma Gandhi National Rural Employment Guarantee Act (MGNREGA)}

Notified on 7 September 2005 and implemented since 1 April 2006, MGNREGA aims at 'enhancing livelihood security by providing at least one hundred days of guaranteed wage employment in a financial year to every household whose adult members volunteer to do unskilled manual work' (Government of India 2008). MGNREGA is a legal framework that embraces a rights-based approach for demand-driven employment. It provides guaranteed wage employment to every rural household at a national minimum wage. The Act covered 200 districts in 2006/07 and was extended to 330 additional districts in 2007/08. All remaining rural areas were covered under the scheme from 1 April 2008.

As a statutory law, MGNREGA is a powerful instrument in the hands of poor, who can hold the government accountable for falling short of its promises. MGNREGA is unprecedented, as no country has tried to implement a legally guaranteed wage employment policy on this scale. From April 2009 to March 2010, 52 million households were provided with employment and 2.8 billion days of work were generated. Total expenditure in 2009/10 was more than 380 billion rupees (US $\$ 8$ billion). The scheme is sponsored by the Ministry of Rural Development, Government of India. Unique features of the Act include a time-bound employment guarantee of 15 days to which State Governments must adhere or be liable for the full cost of an unemployment allowance. Transfers of funds through banks and post office accounts ensure transparency and prevent leakages. An extensive Management Information System (MIS) has also been set up, for real-time tracking of programme implementation and performance.

The Act also mandates that at least one-third of the workforce should be women, who are paid wages equal to men. Wage payments are transferred directly to individual accounts in post offices or local banks. The national average of women's participation is 48 per cent, with several states including Rajasthan, Kerala, Andhra Pradesh and Tamil Nadu having more female than male participants. Women with direct control over their earnings now feel empowered (Jose 2007; Jandu 2008; Khera and Nayak 2009; Pankaj and Tankha 2010; Sudarshan et al. 2010). The policy also ensures equal opportunity to work and equal pay for the elderly and disabled, according to their capacity. Further, service delivery systems have been decentralised with Panchayati Raj (local government institutions) being the principal planning, implementing and monitoring agencies. At the community level, participatory planning and monitoring approaches 
are heavily emphasised. Community social audits are designed to be instrumental in changing the existing dominant and unequal power structures, by putting power in the hands of workers to hold the implementing agencies to account.

\section{Social audits}

While MGNREGA is appreciated as the largest social protection programme in the developing world, social audits have also been nothing less than a revolution in the sphere of public administration and governance, which must be analysed and acknowledged for their contribution. Social audits are seen as a powerful tool to improve implementation and have been recommended for other social protection interventions, including the Integrated Child Development Scheme (ICDS), the Public Distribution System (PDS) and MidDay Meals (Sinha 2008; Swain and Sen 2009). There is also considerable interest in the international community to recommend this rights-based approach in other regions, like southern Africa and Latin America (Philip 2010; World Bank and OAS 2008). This section evaluates social audits from this perspective.

MGNREG law details an extensive monitoring and evaluation system. Some monitoring systems are mandated by the law (i.e. within the Act), while others are initiated by the law (i.e. rules and additional directions to uphold the Act). The Act mandates the formation of statutory bodies: a Central Employment Guarantee Committee (CEGG) at Central level, State Employment Guarantee Committee at State Level (SEGC) and Village Monitoring Committees (VMC) at village level, to monitor implementation. The Government of India envisaged that decentralised and collaborative networks would be needed for monitoring such an expansive policy and therefore included social audits within NREGA (Section 17). It is perhaps the legal statute of the Act that acts as a catalyst for its delivery.

The social audit is a mandatory postimplementation exercise that aims to monitor all projects under MGNREGA at least once every six months. However, it can also be understood in a broader sense, as a continuous process of public vigilance to ensure accountability in the implementation of projects, laws and policies by the community as whole. One simple form of social audit is a public assembly, where all the details of a project are read out. But a more elaborate social audit could include an extensive inspection of status and quality of all works, scrutinising all documents and payments made, investigating discrepancies or grievances raised by the workers and passing resolutions or directions to remedy or investigate the matter, and discussing the findings in a specially convened Gram Sabha (village assembly) (Government of India 2008).

The District Programme Coordinator at the district level and the Programme Officer at the block level are responsible for ensuring the smooth functioning of social audits in their Gram Panchayats (elected village assemblies). All documents related to MGNREGA projects are submitted to the Social Audit Unit (SAU). Most of this information must be accessible online through the MGNREGA website and can also be requested through the Right to Information Act. This allows workers and the general public access to information regarding the work programmes and payments made, to hold implementing agencies accountable for any delays or discrepancies. A special Gram Sabha is convened for the social audit where any member of the Gram Sabha can address their concerns or grievances. All reports on actions taken have to be filed within a month and findings related to contraventions of the Act are considered as complaints and followed up.

The MGNREGA guidelines also provide the States flexibility to contextualise and develop their own social audit structures within the ambit of law. For instance, in Andhra Pradesh, the state government proactively trained resource teams from different civil society organisations (CSOs) to conduct audits (Aakella and Kidambi 2007). The state government trained resource persons and local administrators, gained feedback on the process by piloting social audits in a few districts, built strong information technology infrastructure and involved local leaders in the process to ensure wide public support through a large-scale community participation approach. On the other hand, in Rajasthan, CSOs like Mazdoor Kissan Shakti Sangathan (MKSS), Soochna Evam Rozgar Adhikar Abhiyan, Hum Kissan and others, have spearheaded conducting social audits and jun sunwais (public hearings) in order to track government spending. In Madhya Pradesh, Shylashri Shankar found that the social 
audit team comprised government officials from Revenue and Rural Development, along with engineers, the sarpanch (village head), the secretary and villagers from the Gram Panchayat, who conducted the social audit without any participation of CSOs (Shankar 2010). In Orissa, CSOs have collectively formed a union under the name of Orissa Shramjivi Union (Orissa Workers Union) to strengthen their bargaining power visà-vis the state agencies (Khanna 2010).

Social audits have thus raised the yardsticks of transparency, accountability and community participation to a whole new level. They are a significant vehicle for strengthening decentralisation and deepening democratic processes. However, even with this elaborate design and legal mandate, the performance and quality of social audits have been far from uniform across the states. The effectiveness of laws translating into action crucially depends on the capacity of the people who demand their rights and entitlements and the capacity of the implementation agency to deliver them. Social audits have no doubt infused 'life' into the Panchayati Raj, invigorating community activism with a sense of collective accountability and responsibility. While they have been immensely successful in Andhra Pradesh and parts of Rajasthan (where CSOs are active), they are yet to be fully institutionalised in other parts of the country.

However, this is not to undermine the potential of the social audit. Field research suggests that merely conducting social audits increases the awareness of the people by more than 90 per cent (Pokharel et al. 2008) and smooths the implementation process. They have effectively challenged corruption, with punitive actions taken against corrupt officials, and have successfully recovered embezzled funds (Shankar et al. 2010; Singh and Vutukuru 2010). Social audits are also a transformative measure as they empower the poor with greater bargaining strength to engage directly with the service providers and claim their rights and entitlements. They are a platform for feedback and influencing policy implementation, facilitate people seeking accountability (Goetz and Jenkins 2007) and enhance interaction between participants and government officials (Pokharel et al. 2008). In Andhra Pradesh and Uttar Pradesh, members of the poorest communities have been assuming leadership positions within the community (Priyadarshee and Hossain 2010). While conflicts do initially erupt when villagers question implementing agencies about any discrepancies, as there is an inherent power struggle, once the benefits of social audits are realised, villagers, administration and local CSOs usually work in harmony to coordinate and follow-up on social audits.

But good design does not necessarily translate into action (Joshi 2010). According to the Social Audit Status Report of the Ministry of Rural Development at national level, no social audits were conducted in 13 per cent of districts in 2010/11, ${ }^{3}$ which includes the districts of Bihar, Himachal Pradesh, Manipur, Mizoram, Nagaland, and Jammu and Kashmir. Even in places where social audits have been reported, the possibility that they took place only on record or were conducted unfairly cannot be ruled out. In Uttar Pradesh, studies have noted the problem of elite capture and control of the programme where the gram pradhan (village head) and local-level government officials control the flow of information to the prospective beneficiaries of the social protection programmes (Priyadarshee and Hossain 2010).

Herein lies the weakness of the design. It is the onus of the administration and Gram Panchayats to plan and ensure the smooth functioning of the social audits. Hence, the implementation agency to be audited is itself entrusted with the task of planning and ensuring fair proceedings of the social audit. Also, enforcing local self-governance does not automatically imply economic and social participation of the poor. In contrast to the high participation of women in the programme as workers, their participation in processes like work selection, mobilisation of civil society for social audits, and sharing in controlling and managing assets has not been equally encouraging (Pankaj and Tankha 2010). Further, an independent evaluation of social audits conducted by the Government of India raised serious concerns about the status and quality of social audits conducted in the field. ${ }^{4}$ It noted that some local administrations and village functionaries are unaware of the social audit provisions and procedures, reports submitted online were incomplete and inconsistent and social audits were often marked by low attendance. The quality of social audits is also somewhat reflective of the policy implementation and governance system of the State. 
The detailed procedure outlined was insufficient to ensure that social audits are executed in their true spirit. Unlike other social protection programmes, this policy has evolved. The Government of India, for example, notified MGNREG Audit of Scheme Rules on 30 June $2011,{ }^{5}$ addressing some of the issues raised above. The audit of financial accounts has been separated from the basic social audit process outlined in the Act and operational guidelines. The financial audit of accounts will now be carried out at the district level by a Director, Local Fund Audit or equivalent authority and the report submitted to the State Government. To facilitate the social audits, the state governments must collaborate with an 'independent organisation' like civil society to form a Social Audit Unit (SAU), which in turn is responsible for training resource persons for social audits and facilitating the entire audit process. This model is broadly based on the social audit structure developed by the State Government of Andhra Pradesh, but addresses a wider ambit of issues. For instance, it notifies that the resource group for the social audit should be residents of the same panchayat (Section 5(4)).

Even with the new directions, some fundamental problems in the design remain. There is an implicit issue of weak hierarchy which constraints accountability (Shankar 2010). With the external resource group and presence of independent observers, the implementation agency and auditing unit have been separated, but the relationship between the auditors and local administration is still not explicit, i.e. who is accountable to whom. The government also needs to be cautious of avoiding duplication, as the State Employment Guarantee Council was initially envisaged as a state-level monitoring group and could have been entrusted with the task of SAU, instead of creating a separate unit altogether. Further, with an independent resource group now responsible for social audits, the role of Village Monitoring Committees (VMCs) becomes redundant. Multiple agencies also complicate fixing responsibilities. The concern for enforceability of recommendations and tracking complaints raised by the SAU once they are forwarded to higher levels remains unaddressed. There are delays in redressal once discrepancies have been noted during the social audits with delays in grievance redressal. The design is still weak on punitive measures, especially on sanctions against the errant officials; this is the problem of legitimate authority (Goetz and Jenkins 2007).

Lastly, the government must also ensure protection to whistle-blowers. It has been observed that where CSOs, right to information activists and youth groups have been proactive in disseminating NREGA information and awareness about entitlements and rights, supporting social audits have been faced with hurdles, obstacles, pressures and resistance, especially where they could possibly expose corruption and leakages (Drèze and Khera 2009; Gopal 2009; Vanaik 2008). But amid all the criticisms, there are still interesting cases of civic activists groups successfully collaborating with the government and mobilising the community to assert their rights and demand accountability from the public administration (Aakella and Kidambi 2007).

\section{The way ahead}

While the rights-based framework and detailed social audit mechanism in MGNREGA design is a first step in the right direction, its ideology needs to be embraced fully by the implementing agencies to deliver social justice. Social audit mechanisms are a platform where the government, non-governmental organisations and the public can come together and collaborate to ensure effective policy implementation, monitoring and evaluation. Institutionalising social audits needs capacity building and a change in outlook by India's traditional bureaucracy towards CSOs. Collaborative governance is the key but can be successful only if the state and the organisations work synergistically and not as adversaries. Civil society, through their technical expertise and outreach, can complement the government in monitoring and implementation, while empowering the poor so that they eventually have access to the benefits of the schemes and control over their lives, and take responsibility for and accountability of schemes meant for their welfare. Policy designs must therefore enshrine the rights-based perspective, as well as elucidate a definite role and function of CSOs. Last but not the least, for these organisations to deliver, they must be supported by the administration. This is the only way ahead for MGNREGA and sustainable development. 


\section{Notes}

1 Source: National Rural Employment

Guarantee Act 2005, Report from Second Year April 2006 to March 2007, Ministry of Rural Development, Government of India, www.nrega.nic.in/NREGArpt_eng.pdf (accessed 23 February 2011).

2 The terms Backward Classes and Backward Castes refer to Scheduled Castes (SC), Scheduled Tribes (ST) and Other Backward Classes (OBC) as defined in the Constitution of India vide The Constitution (Scheduled Castes) Order 1950, the Constitution (Scheduled Tribes) Order 1950 and a dynamic list of other socially and educationally

\section{References}

Aakella, K.V. and Kidambi, S. (2007)

'Challenging Corruption with Social Audits', Economic and Political Weekly 42.5: 345-7

Ansell, C. and Gash, A. (2008) 'Collaborative Governance in Theory and Practice', Journal of Public Administration Research and Theory 18.4: 543-71

Drèze, J. and Khera, R. (2009) 'The Battle for Employment Guarantee', Frontline, 3 January

Goetz, A. and Jenkins, R. (2007) 'Citizen Activism and Public Accountability: Lessons from Case Studies in India', in A. Ebrahim and E. Weisband (eds), Global Accountabilities: Participation, Pluralism and Public Ethics, Cambridge: Cambridge University Press

Gopal, K.S. (2009) 'NREGA Social Audit: Myths and Reality', Economic and Political Weekly 44.3: $70-1$

Government of India, Ministry of Rural Development (2008) NREGA Operational Guidelines 2008, 3rd edn, www.nrega.nic.in/ Nrega_guidelinesEng.pdf (accessed 1 April 2011)

Jandu, N. (2008) Employment Guarantee and Women's Empowerment in Rural India, www.righttofoodindia.org (accessed 1 April 2011)

Jose, S. (2007) 'Women, Paid Work, and

Empowerment in India: A Review of Evidence and Issues', Centre for Women's Development Studies, www.cwds.ac.in (accessed 1 April 2011)

Joshi, A. (2010) 'Do Rights Work? Law, Activism, and the Employment Guarantee Scheme', World Development 38.4: 620-30

Kabeer, N. and Cook, S. (2010) 'Introduction: Overcoming Barriers to the Extension of Social Protection: Lessons from the Asia Region', IDS Bulletin 41.4: 1-11 backward classes as per Article 340 of the Indian Constitution. The Constitution provides protective and preferential treatment, like the right to be treated equally and reservations in government and education institutions.

3 Social Audit Report 2010-2011, www.nrega.nic.in/circular/Social_Audit.htm (accessed 21 January 2011).

4 Source: National Level Monitoring of Social Audits in 2009 by Ministry of Rural Development, India.

5 Ministry of Rural Development Notification on 30 June 2011, www.nrega.nic.in/circular/ nrega_audit05072011.pdf (accessed 1 July 2011).

Khanna, P. (2010) 'How Secure is National Rural Employment Guarantee as a Safety Net', paper prepared for the Global Labour University Conference, Berlin, 14-16 September

Khera, R. and Nayak, N. (2009) 'Women Workers and Perceptions of the National Rural Employment Guarantee Act', Economic and Political Weekly 44.43: 49-57

Lanjouw, P. and Murgai, R. (2009) 'Poverty Decline, Agricultural Wages and Nonfarm Employment in Rural India: 1983-2004', Agricultural Economics 40.2: 243-63

Pankaj, A. and Tankha, R. (2010) 'Empowerment Effects of the NREGS on Women Workers: A Study in Four States', Economic and Political Weekly 45.30: 45-55

Philip, K. (2010) 'Towards a Right to Work: The Rationale for an Employment Guarantee in South Africa', paper prepared for the Overcoming Inequality and Structural Poverty in South Africa: Towards Inclusive Growth and Development Conference, Johannesburg, 20-22 September

Pokharel, A.; Aiyar, Y. and Samji, S. (2008) 'Social Audits: From Ignorance to Awareness - The AP Experience', World Bank, Intellicap, Andhra Pradesh: SPIU-Government of Andhra Pradesh Priyadarshee, A. and Hossain, F. (2010) 'Decentralisation, Service Delivery and People's Perspectives: Empirical Observations on Selected Social Protection Programs in India', International Journal of Public Administration 33.12: 752-66

Sabates-Wheeler, R. and Devereux, S. (2007) 'Social Protection for Transformation', IDS Bulletin 38.3: 23-8

Shankar, S. (2010) 'Can Social Audits Count?', ASARC Working Papers 
Shankar, S.; Gaiha, R. and Jha, R. (2010)

'Information and Corruption: The National Rural Employment Guarantee Scheme in India', ASARC Working Papers

Singh, R. and Vutukuru, V. (2010) Enhancing Accountability in Public Service Delivery through Social Audits: A Case Study of Andhra Pradesh, India, Accountability Initiative, New Delhi: Centre for Policy Research

Sinha, D. (2008) 'Social Audit of Midday Meal Scheme in AP', Economic and Political Weekly 43.44: 57-61

Sudarshan, R.M.; Bhattacharya, R. and Fernandez, G. (2010) 'Women's Participation in the NREGA: Some Observations from Fieldwork in Himachal Pradesh, Kerala and Rajasthan', IDS Bulletin 41.4: 77-83
Swain, B. and Sen, P.D. (2009) 'Bridging the Malnutrition Gap with Social Audits and Community Participation', IDS Bulletin 40.4: 95-102

Vanaik, A. (2008) 'NREGA and Death of Tapas Soren', Economic and Political Weekly 43.30: 8-10 World Bank and OAS (2008) Increasing Social Inclusion through Social Guarantees, A Policy Note, Washington DC: Organization of American States, www.sedi.oas.org (accessed 8 August 2011)

Yesudian, C. (2007) 'Poverty Alleviation Programmes in India: A Social Audit', Indian Journal of Medical Research 126.4: 364-73 